\title{
Human Eosinophil Major Basic Protein Induces Airway Constriction and Airway Hyperresponsiveness in Primates
}

Robert H. Gundel, L. Gordon Letts, and Gerald J. Gleich*

Department of Pharmacology, Boehringer Ingelheim Pharmaceuticals, Inc., Ridgefield, Connecticut 06877; and

*Department of Immunology and Medicine, Mayo Medical School, Mayo Clinic and Foundation, Rochester, Minnesota, 55905

\begin{abstract}
We have examined the effects of direct intratracheal instillation of purified eosinophil granule proteins on pulmonary function and airway responsiveness in primates. The results of this study show for the first time that installation of major basic protein (MBP) directly into the trachea of primates results in a significant and dose-related increase in airway responsiveness to inhaled methacholine. Furthermore, MBP and eosinophil peroxidase (EPO) induce a transient bronchoconstriction immediately after instillation that resolves by $1 \mathrm{~h}$ postinstillation. In constrast, instillation of other eosinophil granule proteins had no effect on airway responsiveness or pulmonary function. These data indicate a direct role of the eosinophil in the pathogenesis of airway hyperresponsiveness.

We suggest that the MBP of human eosinophils has an effector role in the pathogenesis of airway hyperresponsiveness which may involve active interaction with resident airway tissue cells. MBP may also mediate altered lung function in various inflammatory lung diseases associated with pulmonary eosinophilia. (J. Clin. Invest. 1991. 87:1470-1473.) Key words: eosinophil granule proteins • airway hyperreactivity • bronchoconstriction • monkeys • asthma
\end{abstract}

\section{Introduction}

Nonspecific airway hyperresponsiveness is defined as an extreme bronchial sensitivity to pharmacological or physiological stimuli and is a characteristic feature of bronchial asthma (1). Whereas the underlying mechanism(s) in the pathogenesis of acute and chronic airway hyperresponsiveness are largely unknown, many recent studies have suggested an active role of nonresident proinflammatory cells that infiltrate specific localities of the lung and which are capable of releasing potent preformed and/or newly generated proinflammatory mediators (2-4). In particular, an association between blood and lung eosinophilia and bronchial asthma has been firmly established, but the mechanism by which the eosinophil might produce

Address correspondence to Robert H. Gundel, Ph.D., Department of Pharmacology, Boehringer Ingelheim Pharmaceuticals, Inc., 90 East Ridge/P.O. Box 368, Ridgefield, CT 06877.

Received for publication 13 August 1990 and in revised form 4 December 1990.

J. Clin. Invest.

(C) The American Society for Clinical Investigation, Inc.

$0021-9738 / 91 / 04 / 1470 / 04 \$ 2.00$

Volume 87, April 1991, 1470-1473 bronchial hyperresponsiveness has been lacking. The most suggestive studies to date have shown that the degree of peripheral blood eosinophilia inversely correlates with the severity of asthma (5).

We have previously demonstrated that repeated antigen inhalation results in the development of persistent airway hyperresponsiveness (6). This chronic airway hyperresponsiveness correlated with both increased numbers of airway eosinophils and the amount of MBP recovered in bronchoalveolar lavage fluid in a primate model of extrinsic asthma. As a result of these findings we reasoned that toxic cationic eosinophil granule proteins, including the major basic protein (MBP). eosinophil cationic protein (ECP), eosinophil peroxidase (EPO), and eosinophil-derived neurotoxin (EDN), might be primary mediators capable of inducing airway hyperresponsiveness and thereby alter lung function. In this report we show for the first time, that eosinophil-granule MBP can induce transient changes in lung function and airway responsiveness in vivo providing direct evidence for an eosinophil contribution to pulmonary dysfunction in primates. Both MBP and EPO caused an acute, transient decrease in airway caliber occurring immediately after instillation which was resolved by 60 min. However, only MBP induced a dose-related increase in airway responsiveness to inhaled methacholine $2 \mathrm{~h}$ postinstillation which returned to baseline values (preinstillation) by $4 \mathrm{~h}$. ECP and EDN had no effect on airway responsiveness or pulmonary function. These studies strongly suggest that MBP, a component of the crystalline core of the eosinophil granule, may be involved in the pathogenesis of acute airway hyperresponsiveness and altered lung function seen in asthma and other allergic inflammatory lung diseases.

\section{Methods}

Animals. The animals used in this study were wild-caught adult male cynomolgus monkeys (Macaca fascicularis) weighing $3.5-7.5 \mathrm{~kg}$ (Charles River Breeding Laboratories, Inc., Primate Imports, Port Washington, NY). Each animal was housed individually in a specially designed open mesh cage and provided with food twice a day and water ad libitum.

Study protocol. Each animal was anesthetized with an intramuscular injection of ketamine (4 mg/kg; Ketaset, Myoderm Medical Supply, Norristown, PA) and xylazine (1 mg/kg; Rompun, Miles Laboratories, Inc., Naperville, IL), intubated with a cuffed endotracheal tube and seated in an upright position in a specially designed support chair. Ketamine ( $4 \mathrm{mg} / \mathrm{kg}$, i.m.) was used as supplemental anesthesia as

1. Abbreviations used in this paper: ECP, eosinophil cationic protein, EDN, eosinophil-derived neutrotoxin, EPO, eosinophil peroxidase, MBP, major basic protein. 
needed. Baseline $R_{\mathrm{rs}}$ was monitored for $15 \mathrm{~min}$ followed by methacholine dose response determinations. After completion of the methacholine dose response each animal received an intratracheal injection of either vehicle or purified eosinophil-derived granule protein. $R_{\mathrm{rs}}$ was then monitored for $1 \mathrm{~h}$ postinstillation, after which the animals were allowed to recover from anesthesia. At 2 and again at $4 \mathrm{~h}$ postinstillation each animal was anesthetized (ketamine/xylazine) and intubated, and methacholine dose response determinations were carried out. The study design was a modified cross-over in which each of the five animals received vehicle instillations and each of the purified granule proteins in random order during separate experiments. Animals were rested 3 to $4 \mathrm{wk}$ between studies.

Intratracheal protein instillations. Eosinophil cytoplasmic granule proteins were isolated and purified as previously described (7). Granule proteins were stored at $-70^{\circ} \mathrm{C}$ until just before intratracheal instillation. Proteins were diluted in PBS ( $\mathrm{pH}$ 7.0) to appropriate concentrations (total volume instilled was $5 \mathrm{ml}$ in each case) immediate before instillation. Proteins were slowly infused into the trachea via a $20-\mathrm{cm}$ long piece of PE 240 tubing attached to a 5-ml syringe.

$R_{r s}$ measurements. Respiratory system impedance $\left(Z_{r s}\right)$ was measured by discrete frequency ( $4-40 \mathrm{~Hz}$ in eight equal logarithmic steps) sinusoidal forced oscillations superimposed on tidal breathing as previously described by Wegner and associates (8). The mean of the real or in-phase component of $Z_{\mathrm{rs}}$ over the entire frequency range was then computed to provide a single value representation of $R_{\mathrm{rs}}$.

Methacholine dose-response determinations. To assess bronchial responsiveness to inhaled methacholine, cumulative dose response curves were constructed by administering increasing concentrations of methacholine until increases in $R_{\mathrm{rs}}$ of $100-200 \%$ were obtained. A vehicle control challenge was performed before the first dose of methacholine. Changes in $R_{\mathrm{rs}}$ were measured at 1 and $3 \mathrm{~min}$ postaerosol challenge. Aerosol challenges were separated by 5-8 min or until $R_{\mathrm{rs}}$ returned to baseline values.

Determination of PC100 values. Linear interpolation on a logarithmic scale was used to estimate the dose at which a $100 \%$ increase in $R_{\mathrm{rs}}$ would have occurred.

Statistical analysis. Changes in methacholine $\mathrm{PC}_{100}$ values were evaluated statistically with the use of Fischer's paired $t$ test. In each case statistical significance was accepted when $P<0.05$. Values are means \pm SE

\section{Results}

The acute effects of purified granule proteins on pulmonary function were evaluated and the results are illustrated in Fig. 1. MBP (1 mg) and EPO (2 mg) induced consistent increases in $\boldsymbol{R}_{\mathrm{rs}}$ occurring immediately after administration, usually peaking at $10 \mathrm{~min}$, that were resolved to preinstillation levels by 60 min. ECP instillation caused an increase in two of the five animals studied while instillation of EDN had no effect on $R_{\mathrm{rs}}$.

The effects of direct intratracheal instillation of purified eosinophil-derived granule proteins on airway responsiveness to inhaled methacholine were assessed and compared to the effect of column buffer instillation in a randomized cross-over study design in five animals. MBP instillation resulted in a dose-related decrease in the $\mathrm{PC} 100$ values for each animal indicating an increase in airway sensitivity to inhaled methacholine (Table I). The mean change in log PC100 values for 500 and $1,000 \mu \mathrm{g}$ MBP were $-0.39 \pm 0.13$ and $-1.02 \pm 0.36$, respectively. MBP-induced increases in airway responsiveness were indicated by a parallel shift to the left in the cumulative methacholine dose response curves (Fig. 2). Airway responsiveness returned to baseline (preinstillation) levels $4 \mathrm{~h}$ post-MBP instillation. In contrast, instillation of ECP, EPO, EPO $+\mathrm{H}_{2} \mathrm{O}_{2}+\mathrm{KI}$, $\mathrm{EDN}$, and column buffer (obtained during protein purification) in the same group of animals did not significantly increase airway responsiveness.

\section{Discussion}

Asthma is characterized by a large infiltration of eosinophils in the bronchial mucosa (9). Studies have shown that eosinophil
A
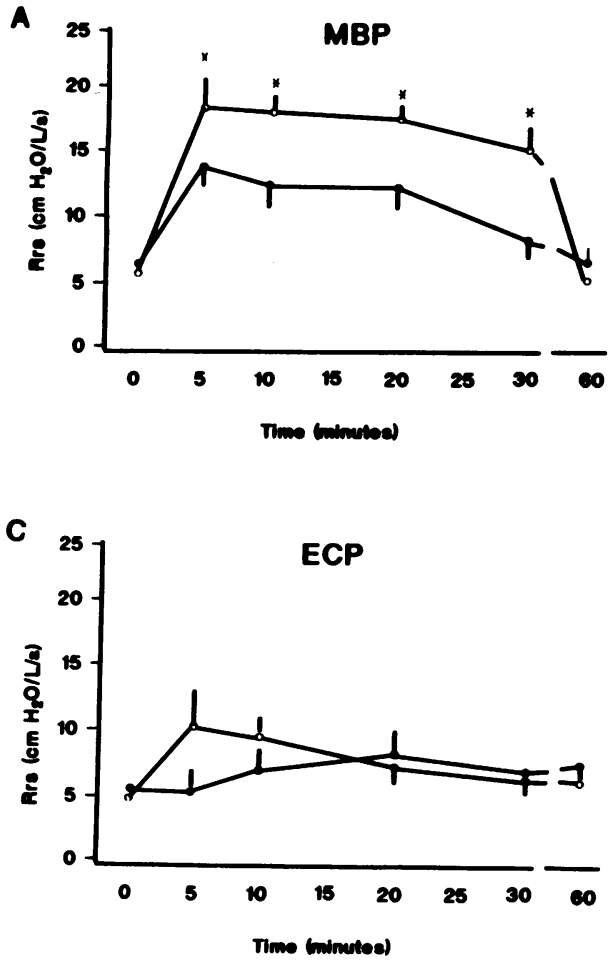
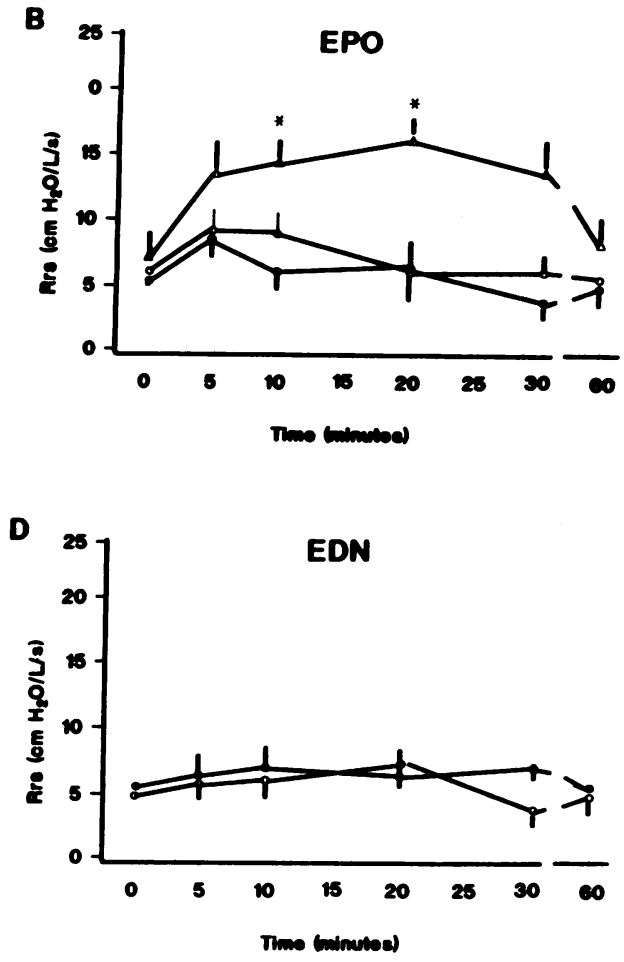

Figure 1. The effect of intratracheal instillation of purified granule proteins on $R_{\mathrm{rs}} .(A) \mathrm{MBP}(0.5$ and $1.0 \mathrm{mg}$ ) administration resulted in a transient increase in $R_{\mathrm{n}}$ which occurred immediately after instillation and resolved by 60 min. (B) EPO (0.5, 1.0, and $2.0 \mathrm{mg}$ ) administration resulted in a non-dose-related increase in $R_{\mathrm{rs}}$ occurring immediately and resolving by $60 \mathrm{~min}$. (C) ECP $(0.5$ and $1.0 \mathrm{mg})$ instillation did not significantly alter $R_{\mathrm{rs}}$ (D) EDN (0.5 and 1.0 $\mathrm{mg}$ ) instillation had no effect on $R_{\mathrm{rs}}$ 
Table I. Effects of Eosinophil Granule Proteins on Airway Responsiveness

\begin{tabular}{lcc}
\hline \multicolumn{1}{c}{ Substance } & Dose & Change in log methacholine PC100 \\
\hline & $m g$ & \\
MBP & 0.5 & $-0.39 \pm 0.13^{*}$ \\
& 1.0 & $-1.02 \pm 0.36^{*}$ \\
ECP & 0.5 & $0.18 \pm 0.49$ \\
& 1.0 & $0.37 \pm 0.17$ \\
EPO & 0.5 & $-0.03 \pm 0.27$ \\
& 1.0 & $-0.15 \pm 0.21$ \\
EPO $+\mathrm{H}_{2} \mathrm{O}_{2}+\mathrm{KI}$ & 2.0 & $-0.09 \pm 0.20$ \\
EDN & 1.0 & $-0.18 \pm 0.14$ \\
Buffer & 1.0 & $0.04 \pm 0.06$ \\
& - & $0.02 \pm 0.08$ \\
\hline
\end{tabular}

${ }^{*} P<0.05, x \pm \mathrm{SD}, n=5 . \mathrm{H}_{2} \mathrm{O}_{2}\left(2 \times 10^{-5} \mathrm{M}\right), \mathrm{KI}\left(10^{-4} \mathrm{M}\right)$.

counts and MBP levels are elevated in BAL fluid obtained from asthmatics as compared to nonasthmatics and correlate with the severity of asthma (10). Furthermore, MBP has been shown to be localized on damaged epithelial surfaces and in mucus plugs in the airways of patients who died from status asthmaticus (11). One hypothesis of the mechanism of action of eosinophil involvement in bronchial hyperresponsiveness has therefore focused on the cytotoxic effects of the eosinophil-derived granule proteins (reviewed in reference 11). Data supporting this hypothesis come from studies demonstrating that each of the granule proteins, with the exception of EDN, are toxic to guinea pig tracheal epithelium resulting in exfoliation and ciliostasis $(12,13)$. Exfoliation of epithelial cells may lead to hyperresponsive airways as many studies have demonstrated increased responsiveness of airway smooth muscle to constrictor mediators after the epithelium has been removed in vitro (11). However, more recent studies have shown that MBP, at subcytotoxic concentrations, can increase the responsiveness of smooth muscle, indicating that changes in responsiveness can occur with an intact epithelium (14). Furthermore, data from other studies have indicated that MBP-induced increases in smooth muscle responsiveness may require an intact epithelium and suggest the release of an epithelial-derived constricting factor(s) and/or the inhibition of a relaxing factor(s) (15, 16). In previous studies, we demonstrated that repeated antigen inhalation caused chronic airway eosinophilia and airway hyperresponsiveness in primates $(6,17)$. In those studies, the increase in airway responsiveness directly correlated with the increase in airway eosinophils (assessed by bronchoalveolar lavage BAL and histological examination) and the level of BAL MBP. Histological examination of lung tissue demonstrated in all cases an intact epithelium indicating that the increase in airway responsiveness occurred without cell denudation raising the intriguing possibility that it may be dependent on epithelial cell integrity. The results of our present study are consistent with this hypothesis in that increased responsiveness occurred $2 \mathrm{~h}$ post-MBP instillation and returned to baseline (preinstillation) values by $4 \mathrm{~h}$. Thus, exfoliation of airway epithelial cells seems unlikely to be involved in the presently observed increase in airway responsiveness. A more likely explanation may involve the interaction of MBP with resident luminal/tissue cells lining the airways. This interaction appears to be a
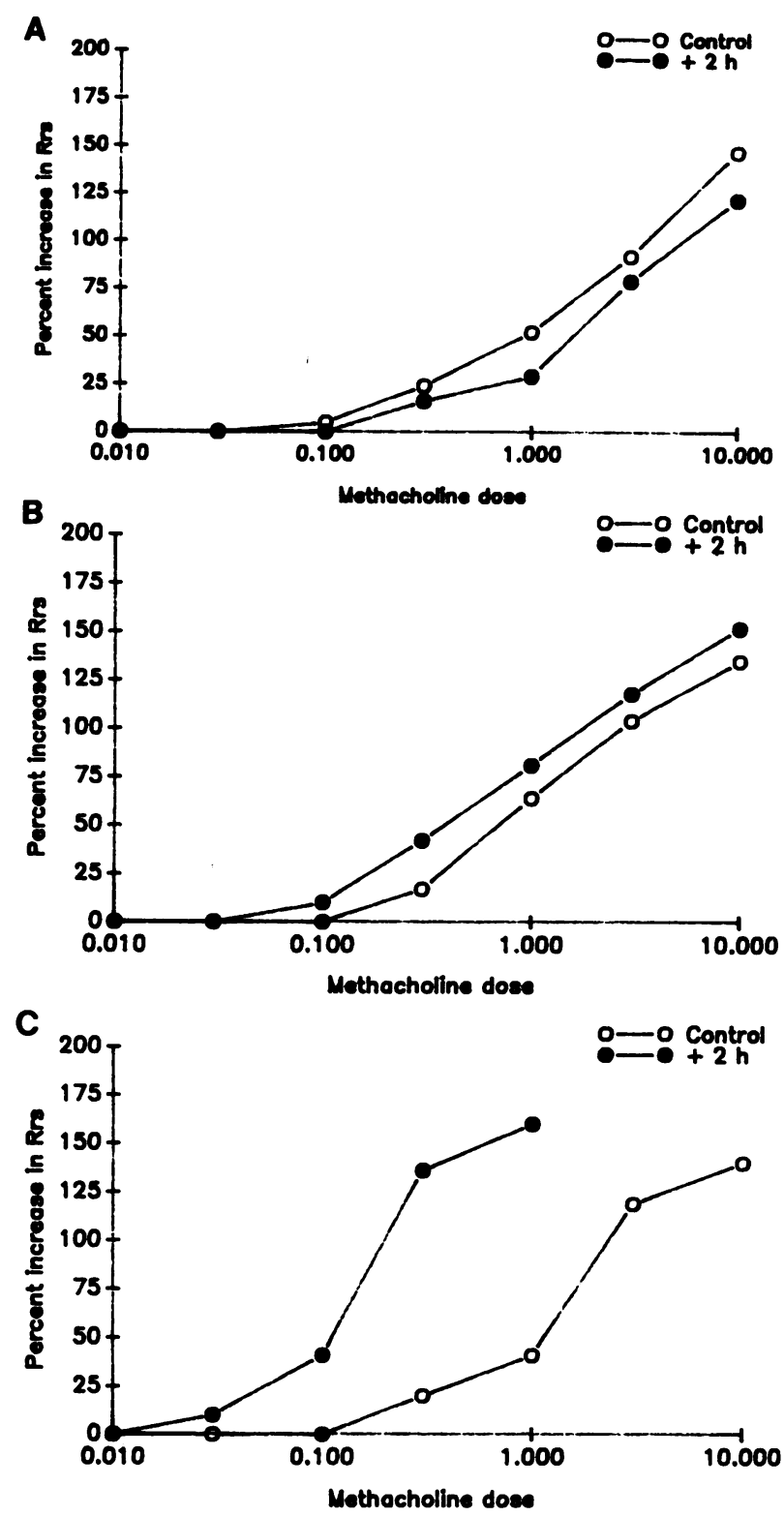

Figure 2. Methacholine dose response curves from one animal receiving intratracheal instillation of $(A)$ column buffer, $(B)$ MBP $(0.5$ $\mathrm{mg}$ ), and (C) MBP (1.0 mg). MBP instillation resulted in a dose-related increase in airway responsiveness to inhaled methacholine as indicated by a shift to the left in dose response curves. The administration of column buffer had no effect on airway responsiveness.

unique property of MBP as the other highly cationic molecules did not produce the same effect on airway sensitivity. Thus, the actions of MBP on the airways cannot be solely explained by cationic charge alone. Other studies have demonstrated differential effects of MBP as well. For example, Zheutlin and coworkers have shown that MBP induces histamine release from human basophils, whereas equimolar concentrations of ECP and EDN were ineffective (7). Thus, MBP may induce the release of bronchoactive and vasoactive chemical mediators which may alter the responsiveness of airway smooth muscle and contribute to the pathogenesis of asthma and other inflammatory airway diseases. 


\section{Acknowledgments}

This work was supported in part by grants from the National Institutes of Health, AI09728 and RR00585, and from the Mayo Foundation.

\section{References}

1. Cockcroft, D. W., D. N. Killian, J. J. Mellon, and F. E. Hargreave. 1977. Bronchial reactivity to inhaled histamine: a method and clinical survey. Clin. Allergy. 7:235-239.

2. Lowhagen, O., and S. Rak. 1985. Modification of bronchial hyperreactivity after treatment with sodium cromoglycate during pollen season. J. Allergy Clin. Immunol. 75:460-467.

3. Lanes, S., J. S. Stevenson, E. Codias, A. Hernandez, M. W. Seilczak, A Wanner, and W. M. Abraham. 1986. Indomethacin and FPL-55231 inhibit antigen-induced airway hyperresponsiveness in sheep. J. Appl. Physiol. 61:864-872.

4. Marsh, W. R., C. G. Irvin, K. R. Murphy, B. L. Behrens, and G. L. Larsen, 1985. Increases in airway reactivity to histamine and inflammatory cells in bronchoalveolar lavage after the late asthmatic response in an animal model. Am. Rev. Respir. Dis. 131:875-879.

5. Cockcroft, D. W., R. E. Ruffin, J. Dolovich, and F. E. Hargreave. 1977. Allergen-induced increase in bronchial reactivity. Clin. Allergy. 7:503-513.

6. Gundel, R. H., M. E. Gerritsen, and C. D. Wegner. 1990. Repeated antigen inhalation results in a prolonged airway eosinophilia and airway hyperresponsiveness in primates. J. Appl. Physiol. 68:779-786.

7. Zheutlin, L. M., S. J. Ackerman, G. J. Gleich, and L. L. Thomas. 1984. Stimulation of basophil and rat mast cell histamine release by eosinophil granulederived cationic proteins. J. Immunol. 133-2180-2185.
8. Wegner, C. D., A. C. Jackson, J. D. Berry, and J. R. Gillespie. 1984. Respiratory mechanics in monkeys measured by forced oscillations. Annu. Rev. Physiol. 55:47-61.

9. Dunnill, M. S. 1960. The pathology of asthma with special reference to changes in the bronchial mucosa. J. Clin. Pathol. 13:27-33.

10. Wardlaw, A. J., S. Dunnette, G. J. Gleich, J. V. Collins, and A. B. Kay. 1988. Eosinophils and mast cells in bronchoalveolar lavage in subjects with mild asthma. Am. Rev. Respir. Dis. 137:62-69.

11. Gleich, G. J. 1990. The eosinophil and bronchial asthma: current understanding. J. Allergy Clin. Immunol. 85:422-436.

12. Frigas, E., D. A. Loegering, and G. J. Gleich. 1980. Cytotoxic effects of the guinea pig eosinophil major basic protein on tracheal epithelium. Lab. Invest. 42:35-43.

13. Motojima, S., E. Frigas, D. A. Loegering, and G. J. Gleich. 1989. Toxicity of eosinophil cationic proteins for guinea pig tracheal epithelium in vitro. Am. Rev. Respir. Dis. 139:801-805.

14. Flavahan, N. A., N. R. Slifman, G. J. Gleich, and P. M. Vanhoutte. 1988 Human eosinophil major basic protein causes hyperreactivity of respiratory smooth muscle: role of the epithelium. Am. Rev. Respir. Dis. 138:685-688.

15. White, S. R., S. Ohno, J. S. Blake, N. M. Munoz, G. J. Gleich, J. Solway, and A. R. Leff. 1991. Epithelial-dependent contraction of airway smooth muscle caused by eosinophil MBP. Am. J. Physiol. In press.

16. Brofman, J. D., S. R. White, J. S. Blake, N. M. Munoz, G. J. Gleich, and A. R. Leff. 1989. Epithelial augmentation of trachealis contraction caused by major basic protein of eosinophils. J. Appl. Physiol. 66:1867-1873.

17. Gundel, R. H., M. E. Gerritsen, and C. D. Wegner. 1989. Antigen-Sepharose beads induce airway eosinophilia and airway hyperresponsiveness in cynomolgous monkeys. Am. Rev. Respir. Dis. 140:629-633. 